\title{
GAYA RETORIKA KEPALA NEGARA RI: ANALISIS KOMPARATIF SUSILO BAMBANG YUDHOYONO (SBY) DAN JOKO WIDODO
}

\author{
Dwi Sulistiyani, Mukaromah \\ Universitas Dian Nuswantoro \\ dwisulis014@gmail.com
}

\begin{abstract}
Abstrak
Penelitian ini membahas tentang kanon gaya retorika (Chanon Rethoric) kepala negara, yaitu Susilo Bambang Yudhoyono dan Joko Widodo. Baik Susilo Bambang Yudhoyono maupun Joko Widodo memiliki gaya retorika yang berbeda dan karakter pribadi yang masing-masing memiliki keunikan. Penelitian ini bertujuan untuk mengidentifikasi gaya retorika SBY dan Jokowi, berfokus pada saat mereka memimpin Sidang Kabinet Paripurna. Dalam penelitian, penulis menggunakan teori kode verbal dan kode nonverbal dan menggunakan pendekatan kualitatif dengan metode analisis deskriptif dengan teknik triangulasi. Objek penelitian ini berupa video rekaman pidato SBY dan Jokowi dalam memimpin sidang kabinet paripurna. Hasil penelitian menunjukkan bahwa dalam menyampaikan materi pidato, gaya bicara SBY teratur, kaku, dan menggunakan istilah yang panjang. SBY lebih mengutamakan kode verbal dibandingkan dengan non verbal karena mampu membentuk bahasa (langue) yaitu fonologi (tata bunyi), morfologi (pembentukan kata), dan sintaksis (pembentuk kalimat). Gerakan bahasa isyarat adaptor SBY yang paling banyak ditemui terutama objek-adapter yang ditujukan pada gadget canggih yang dibawanya untuk membantunya mengingat isi materi pidato. Sedangkan gaya retorika Jokowi menggunakan bahasa percakapan (parole), yaitu menggunakan bahasa keseharian dan mudah dipahami oleh semua kalangan, kata-kata yang merakyat, dan lebih to the point. Bahasa tubuh (body language) Jokowi juga membantu memudahkan pesan pidato dapat tersampaikan dengan jelas. Hal ini menandakan bahasa non verbal kinesics lebih dominan karena ekspresi Jokowi berubah-ubah mengikuti pesan yang disampaikan dan gerakan yang dilakukan.
\end{abstract}

Kata Kunci: Kanon Retorika, Gaya Retorika, Teori Kode Verbal dan Nonverbal.

\begin{abstract}
This study discusses the Chanon Rethoric head of state, namely Susilo Bambang Yudhoyono and Joko Widodo. Both Susilo Bambang Yudhoyono (SBY) and Joko Widodo have different styles of rhetoric and personal character that each has its own uniqueness. This study aims to identify the rhetorical style of SBY and Jokowi, focusing as they lead the Plenary Cabinet Session. In the study, the author uses verbal code theory and nonverbal code and uses a qualitative approach with descriptive analysis method with triangulation technique. The object of this research is a video recording of SBY and Jokowi's speech in leading the plenary cabinet session. The results showed that in delivering speech material, SBY's speech style is regular, rigid, and uses long term. SBY prefers verbal code compared with non verbal because it is able to form language (langue) that is phonology (sound system), morphology (word formation), and syntax (forming of sentence). The most widely used SBY adapter language gesture is particularly the objectadapter aimed at the advanced gadgets it carries to help him remember the content of the speech material. While Jokowi rhetoric style using the language of conversation (parole), which uses the language of everyday and easily understood by all circles, the words populist, and more to the point. Body language (body language) Jokowi also help ease speech messages can be conveyed clearly. This indicates that non-verbal language kinesics is more dominant because Jokowi's expression changes with the message and movements.
\end{abstract}

Keywords: Rethorical Canon, Rethorical style, Verbal Code and nonverbal Theory 


\section{Pendahuluan}

Sebagai makhluk sosial, manusia selalu berkomunikasi dengan orang lain. Setiap manusia dituntut terampil berkomunikasi, terampil menyatakan pikiran, gagasan, ide, dan perasaan. Terampil menangkap informasi-informasi yang didapat dan terampil pula menyampaikan informasi-informasi yang diterima. Dalam kehidupan bermasyarakat dan berbudaya, keterampilan berbicara juga memiliki peranan yang sangat penting. Dengan berbicara manusia berhubungan satu dengan yang lain, sehingga memungkinkan dirinya hidup bersama dalam berbagai tatanan masyarakat. Berbicara merupakan alat komunikasi yang efektif dan efesien.

Berbicara yang dapat meningkatkan kualitas eksistensi (keberadaan) ditengah-tengah orang lain bukanlah sekedar berbicara. Berbicara yang menarik (atraktif), bernilai informasi (informatif), menghibur (rekreatif), dan berpengaruh (persuasif) membutuhkan teknik atau strategi khusus.Secara umum berbicara dapat diartikan sebagai suatu penyampaian maksud (ide, pikiran, isi hati) seseorang kepada orang lain dengan menggunakan bahasa lisan sehingga maksud tersebut dapat dipahami orang lain. (Haryadi dan Zamzani, 2000:72) Setiap kegiatan berbicara yang dilakukan manusia selalu mempunyai maksud dan tujuan. Tujuan utama berbicara adalah untuk berkomunikasi. Selain untuk berkomunikasi juga bertujuan untuk meyakinkan pendengar, menghendaki tindakan atau reaksi fisik pendengar, memberitahukan, dan menyenangkan para pendengar. (Gorys Keraf dalam St. Y. Slamet dan Amir, 1996: 46-47)

Ada banyak manfaat yang bisa dirasakan langsung jika seseorang terampil berbicara, yaitu memperlancar komunikasi antar sesama, mempermudah pemberian berbagai informasi, meningkatkan kepercayaan diri, dan meningkatkan kewibawaan diri. (Musaba, 2012:13). Kemampuan berbicara di depan umum (public speaking) dan presentasi (presentation) secara efektif dengan bahasa lisan (verbal) merupakan salah satu penunjang keberhasilan seseorang, terutama mereka yang menggeluti pekerjaan yang bersinggungan dengan orang lain. Sebab, sebagai makhluk hidup, manusia harus melakukan komunikasi dengan cara menyatakan ekspresi lewat kemampuan presentasi dan berbicara.

Kemampuan public speaking juga sangat penting dimiliki oleh orang-orang dengan posisi yang menelurkan ide, analisis, dan profesi-profesi yang mengharuskan berhubungan dengan banyak orang. Beragam profesi dalam perkembangannya membutuhkan kemampuan public speaking dan presentasi. Politisi, pejabat pemerintah, manajer perusahaan, pegawai atau karyawan, ilmuwan, pengusaha, dan guru, suatu saat pasti dituntut untuk berbicara atau memberi presentasi di depan orang banyak, dan kemampuannya berbicara itu secara langsung maupun tidak langsung akan membawa dampak bagi pekerjaan atau diri pribadinya. Termasuk dalam hal ini adalah jabatan Kepala Negara. Seorang Kepala Negara atau Presiden harus memiliki kemampuan berbicara yang mampu memotivasi dan membakar semangat rakyat. Maka dari itu, kepala negara seharusnya berbicara berdasarkan seni berbicara yang dikenal dengan istilah Retorika.

Kata retorika berasal dari bahasa Yunani yakni Rhetor yang berarti mahir berbicara (Sunarjo, 1983:31). Retorika didefinisikan sebagai the art of constructing arguments and speechmaking (Seni membangun argumentasi dan seni berbicara) (Littlejohn, 2008:50). 
Pengertian retorika yang lebih dalam lagi yaitu ilmu yang mempelajari cara mengatur komposisi kata-kata agar timbul kesan yang telah dikehendakinya pada diri khalayak (Rahmat, 2001:10). Fungsi retorika sebagai komunikasi persuasif. Kualitas persuasi dari retorika bergantung kepada tiga aspek pembuktian, yaitu logika (logos), etika (ethos), dan emosional (pathos). Pembuktian logika berangkat dari argumentasi pembicara atau orator itu sendiri, pembuktian etis dilihat dari bagaimana karakter dari orator terungkap melalui pesan-pesan yang disampaikannya dalam orasi, dan pembuktian emosional dapat dirasakan dari bagaimana transmisi perasaan dari orator mampu tersampaikan kepada khalayak. (http://www.rhetoricring.com/overview/, diakses pada 17 Maret 2017, 11:45 WIB). Setiap orang yang bertutur sebenarnya terlibat dengan retorika. Retorika dimanfaatkan ketika seseorang tengah mempersiapkan tuturnya, menata, serta menampilkannya. Pemanfaatan ini sebagian besar didorong oleh keinginan untuk mendapatkan tutur yang menarik atau tutur yang mampu mempengaruhi orang lain atau mampu mempersuasi orang lain. Pengetahuan tentang retorika dalam pidato dapat memberikan ciri atau ragam tutur yang tentunya berbeda dengan tutur lainnya. (Oka dan Basuki, 1990:6)

Pidato adalah pengungkapan pikiran dalam bentuk kata-kata yang ditujukan kepada orang banyak atau wacana yang disiapkan untuk diucapkan di depan khalayak. (KBBI, 1990: 681) Pidato yang baik dapat memberikan suatu kesan positif bagi orang-orang yang mendengar pidato tersebut. Seseorang yang melaksanakan pidato didepan umum dengan lantang dan lancar, belum tentu dapat merebut jiwa para pendengar, bahkan bisa juga, justru meninggalkannya karena hati mereka tidak sesuai dengan isi pesan yang disampaikan dan ucapan dalam berpidato. Pemimpin tidak bisa melepaskan diri dari berpidato. Pemimpin adalah seorang pribadi yang memiliki kecakapan dan kelebihan, khususnya kecakapan/ kelebihan di satu bidang, sehingga dia mampu mempengaruhi orang lain untuk bersama-sama melakukan aktivitas-aktivitas tertentu demi pencapaian satu atau beberapa tujuan. (Kartini Kartono, 1994 : 181).

Bagi pemimpin, retorika adalah alat penting untuk mempengaruhi dan menguasai manusia. Rasanya sulit bagi seorang pemimpin untuk mencapai reputasi dan prestasi tanpa penguasaan retorika. Bagaimana ia bisa menyebarluaskan dan menanamkan idenya pada benak tiap individu tanpa retorika. Pidato menjadi kunci sekaligus medium bagi pemimpin untuk melakukan respons, memberikan kritik, memberika ajakan dan petuah hingga menanggapi berbagai persoalan. Pidato yang baik dapat memberikan suatu kesan positif bagi orang-orang yang mendengar pidato tersebut terutama ketika menjabat sebagai presiden mutlak harus seorang retor atau orator yang mampu membawa rakyat ke arah yang dituju bersama-sama, berperan serta dalam mengisi pembangunan untuk mencapai kemakmuran hidup. Atau pemimpin yang banyak diam tidak banyak bicara di mana rakyatnya tidak tahu apa yang jadi kebijakan pemimpinnya karena tidak adanya komunikasi.

Berpidato yang baik menjadi gaya tersendiri bagi seorang presiden. Tentu setiap presiden atau kepala negara mempunyai gaya retorika yang berbeda dalam mempersuasi rakyat. Berlatar belakang kemiliteran, presiden SBY (Susilo Bambang Yudoyono) mempunyai 
karakteristik pembawaan yang tegas disiplin dan berani. Mengawali jabatan melalui Pemilu pilpres yang demokratis atau dipilih langsung oleh rakyat tahun 2004, presiden keenam ini berhasil menjabat selama dua periode. SBY berhenti sebagai presiden karena dalam masa jabatan, presiden hanya diperbolehkan menjabat selama dua periode. Presiden dan Wakil Presiden memegang jabatan selama lima tahun, dan sesudahnya dapat dipilih kembali dalam jabatan yang sama, hanya untuk satu kali masa jabatan (Pasal 7 UUD 1945).Presiden selanjutnya yang menggantikan posisi SBY yaitu presiden Joko Widodo.

Jokowi memiliki karakter dan gaya komunikasi yang berbeda dengan SBY. Dapat kita lihat secara umum dikalangan beberapa pemerhati, penerjemah kepresidenan RI Muhammad Iqbal Sirie, memiliki pendapat mengenai gaya bertutur dua presiden tersebut. SBY dan Jokowi, keduanya mempunyai gaya komunikasi yang berbeda dalam bertutur diberbagai pertemuan berlevel internasonal. Perbedaan terletak pada pemilihan kata-kata yang disampaikan kepada pendengarnya. Presiden SBY cenderung menggunakan bahasa-bahasa formal. Sementara presiden Jokowi lebih menyukai penggunaan istilah yang sederhana. (Rimadi, 2015, http://m.liputan6.com/news/read/2362224/begini-gaya-bahasa-Jokowi-dan-sby-menurutpenerjemah-kepresidenan, diakses pada 18 April 2017, 07:12 WIB)

Berdasarkan uraian diatas, peneliti tertarik untuk menganalisis gaya retorika Presiden SBY (Susilo Bambang Yudoyono) dengan Presiden Joko Widodo yang sama-sama dipilih langsung oleh rakyat serta memiliki karakter yang berbeda dalam kepemimpinannya. Gaya beretorika dua presiden tersebut dapat dilihat dari pidato presiden dalam memimpin sidang kabinet paripurna. Dalam sidang kabinet paripurna, presiden mengumpulkan para menteri untuk membahas dan memecahkan masalah-masalah yang dihadapi oleh negara. Alasan peneliti memilih video pidato pengantar presiden pada sidang kabinet paripurna, yaitu karakter kepemimpinan SBY (Susilo Bambang Yudoyono) dan Jokowi melalui gaya retorika dalam mengarahkan menteri-menterinya dapat dilihat. Itulah beberapa yang dapat dijadikan penulis sebagai argumentasi, mengapa kasus ini diangkat dan dijadikan sebuah penelitian penting yang diberi judul "Retorika Kepala Negara RI: Analisis Komparatif SBY (Susilo Bambang Yudoyono) dan Joko Widodo".

\section{Tujuan Penelitian}

Melihat permasalahan yang sudah dikemukakan di atas, tujuan penelitian ini adalah menganalisis gaya retorika mantan Presiden SBY (Susilo Bambang Yudoyono) dengan Presiden Joko Widodo. Obyek diamati dari video pidato pengantar Presiden dalam Sidang Kabinet Paripurna yang dimuat di situs resmi Kementerian Sekretariat Negara RI.

\section{Kerangka Teori}

Pada setiap penelitian diperlukan adanya kerangka berpikir sebagai pijakan atau sebagai pedoman dalam menentukan arah dari penelitian, hal ini diperlukan agar penelitian tetap terfokus pada kajian yang akan diteliti. Berikut ini adalah bagan alur kerangka berpikir dalam penelitian ini. Kerangka pemikiran yang ingin peneliti paparkan, yakni: 
Bagan 1

Kerangka Pemikiran

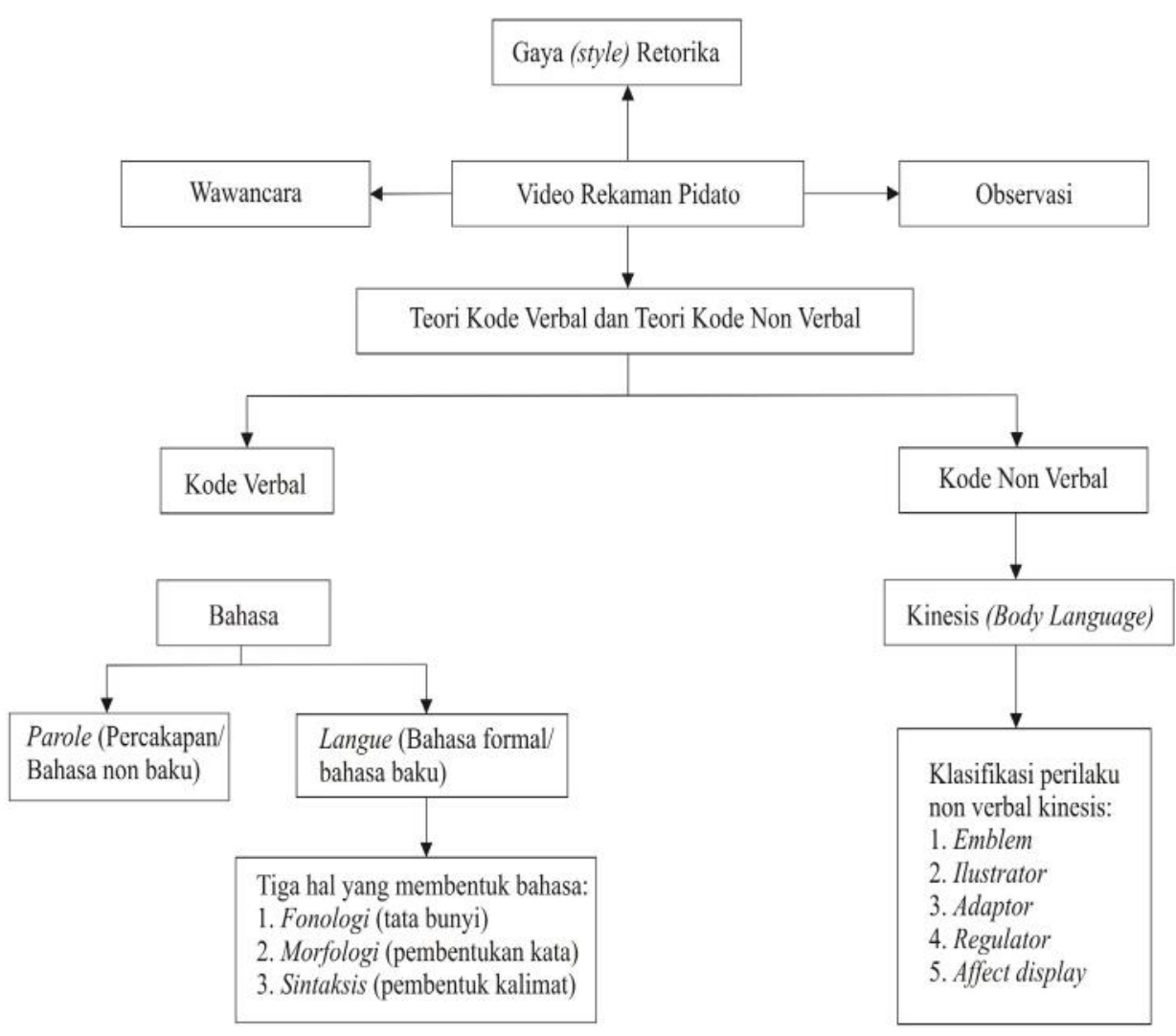

Sumber: Olahan peneliti

\section{Metode Penelitian}

Metode yang digunakan dalam penelitian ini adalah pendekatan kualtitatif dengan jenis penelitiannya adalah analisis deskriptif. Pendekatan kualitatif didasarkan pada penafsiran dengan konsep-konsep yang umumnya yang tidak memberikan angka numerik seperti etnometodologi, dan metode ini dianggap berdasarkan interpretatif (Stokes, 2006:15).

Dengan menggunakan analisis deskriptif dimana peneliti berusaha melukiskan secara sitematis fakta atau karakteristik populasi tertentu atau bidang tertentu secara faktual dan cermat. Fungsi analisis deskriptif adalah untuk memberikan gambaran umum tentang data yang telah diperoleh. Gabaran umum ini bisa menjadi acuan untuk melihat karakteristik data yang kita peroleh. (Rakhmat, 2005:22)

Deskriptif yaitu data yang dikumpulkan berupa kata-kata, gambar dan bukan angkaangka, sehingga laporan penelitian akan berisi kutipan-kutipan data untuk memberikan gambaran penyajian laporan tersebut. Peneliti menggunakan wawancara, observasi, dokumentasi-dokumentasi, rekaman bukti fisik. (Kriyantono, 2007: 102)

Objek dari penelitian ini adalah video rekaman pidato mantan Presiden SBY (Susilo Bambang Yudoyono) dan Presiden Joko Widodo dalam sidang kabinet paripurna yang diunggah oleh Sekretariat Kabinet ke situs youtube.com, merupakan akun youtube resmi milik Sekretariat Kabinet RI yang berisikan video kegiatan kabinet dan Sekretariat Kabinet. 
Pada penelitian ini, penarikan kesimpulan peneliti menggunakan teknik triangulasi, yakni usaha mengecek keabsahan temuan riset dengan menggunakan lebih dari satu teknik pengumpulan data untuk mendapatkan hasil yang sama (Kriyantono, 2006: 72).

\section{Hasil Penelitian dan Pembahasan}

a. Penyajian Data Gaya Retorika Susilo Bambang Yudhoyono dan Joko Widodo pada Pidato Pengantar Sidang Kabinet Paripurna

Berikut ini adalah hasil analisa data gaya retorika SBY (Susilo Bambang Yudhoyono) dengan Joko Widodo melalui video pidato pengantar Presiden pada Sidang Kabinet Paripurna yang diunduh dari akun resmi Youtube milik Kementerian Sekretariat Negara RI.

1. Gaya Retorika Susilo Bambang Yudhoyono

Objek penelitian yang penulis pilih untuk menganalisis gaya retorika Susilo Bambang Yudhoyono (SBY) yaitu video pidato pengantar Presiden pada Sidang Kabinet Paripurna, yang membahas tentang APBN tahun 2014. Video pidato berdurasi 9 menit 50 detik ini berlangsung pada 14 November 2013 di Istana Negara, Jakarta.

Pada pidato pengantar Sidang Kabinet Paripurna, Susilo Bambang Yudhoyono (SBY) membuka pidato dengan mengucap salam sambil membenarkan posisi iPad nya. Pada pembukaan pidato, SBY langsung menyebut pokok persoalan yang akan dibicarakan. Di setiap pembawannya dalam berpidato, SBY menggunakan iPad untuk membantunya mengingat isi pidato yang akan disampaikan. Beberapa kali menengok iPad yang berdiri tegak di depan beliau.

SBY berpidato dengan posisi duduk, badan tegak, dan tangan menompang diatas meja. Dengan bahasa baku yang runtut, tertata rapi, dan intonasi yang stabil. Mengungkapkan setiap kata dengan jelas (clarity) dan menggunakan kata berona (colorfull word) untuk melukiskan sikap, perasaan, dan keadaan. Misalnya, kata "bergejolak" yang digunakan SBY untuk mengungkan kondisi Ekonomi. Selalu memberikan penekanan (stressing) disetiap kata yang dianggap penting. SBY terlihat tenang dalam menyampaikan pesan. Sesekali menengok ke iPadnya sehingga gerakan tubuh yang sering terlihat hanya bagian kepala.

\section{Gambar. 1}

Gerakan tangan SBY (Susilo Bambang Yudhoyono)

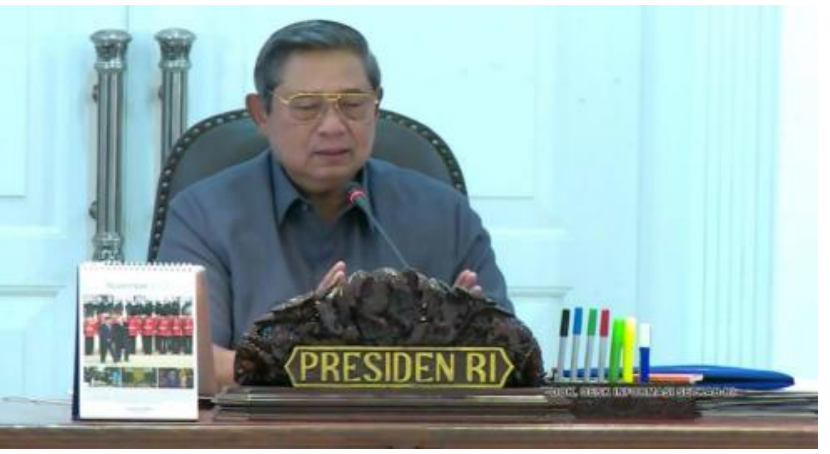

Sumber: Pidato Pengantar SBY pada Sidang Kabinet Paripurna 14 November 2013 di Istana Negara, Jakarta diunduh dari https://www.youtube.com 
Pada menit ke-4, SBY mulai melakukan gerakan tangan. Hanya gerakan kecil, bagian siku kebawah dan tidak sampai mengangkat lengannya. Dalam hal ini, SBY tidak terlalu aktif dalam melakukan gerakan. Menit ke-9, SBY memainkan iPad nya dengan jari telunjuk, menscroll kebawah untuk menaikkan kalimat yang hendak dibaca. Masih fokus dengan iPadnya, namun SBY terus berbicara sekalipun pandangannya tertuju ke arah alat canggih tersebut. Pada menit ke-9 detik ke-44, SBY menutup pidato dengan kalimat yang singkat.

Hasil wawancara dengan Siswo Purnomo selaku protokoler walikota Semarang pada 28 April 2017, menjelaskan bahwa Susilo Bambang Yudhoyono (SBY) memiliki latarbelakang kemiliteran sehingga pembawaannya sangat tegas, disiplin, dan gagah berani. Dalam menyampaikan materi pidato, gaya bicara SBY teratur, kaku, dan menggunakan istilah yang panjang dengan bahasa-bahasa formal. Kalimat-kalimat SBY sangat runut dan lancar.

Masing-masing presiden memiliki style atau gaya retorika tersendiri sehingga kita tidak bisa menilai pidato siapa yang lebih bagus. Dalam berpidato, SBY lebih mengarah ke data atau isu-isu apa yang dihadapi. SBY berpidato dengan posisi duduk, hal ini tidak salah karena level posisi SBY lebih tinggi dari audiens yaitu para menteri. Dari segi pendapat Siswo Purnomo, pidato dengan duduk apabila posisi antara pendengar dan pemberi pidato itu internal, namun jika posisi audiensnya ada yang lebih tinggi atau tidak dari lingkungan internal organisasi, maka seorang pembicara diharuskan untuk berdiri.

Sikap SBY cenderung terlalu berhati-hati, hal ini terlihat dari mimik wajah menunjukkan keseriusan, bahasanya yang formal serta intonasi yang stabil sehingga menimbulkan kesan tegas. Dalam menyampaikan pidatonya, SBY dibantu gadgetcanggih yaitu komputer tablet atau iPad. IPad tampak berdiri tegak di depanSBY. Beberapa kali, SBY mengarahkan pandangannya ke perangkat berwarna putih. Dengan iPad tersebut, SBY dengan mudah dapat membaca tulisan-tulisannya.SBY sosok yang perfeksionis, dalam memimpin sidang kabinet paripurna, beliau memakai pakaian dinas yang menjadi ciri khasnya dengan rambut yang disisir rapi.

\section{Gaya Retorika Joko Widodo}

Video pidato yang penulis pilih sebagai Objek penelitian dalam menganalisis gaya retorika Joko Widodo, tidak berbeda dengan kegiatan SBY sebagai kepala Negara. Pidato pengantar Presiden pada Sidang Kabinet Paripurna dengan pembahasan RKP (Rencana Kerja Pemerintah) 2017. Video berdurasi 7 menit 41 detik, berlangsung pada hari Rabu tanggal 10 Februari 2016 di Istana Negara, Jakarta.

Pada pembukaan pidato, tangan kanan Jokowi membenarkan mikropon sedangkan tangan kirinya memegang kertas. Jokowi menunduk membuka catatan pidatonya. Mengucap salam pembukaan dengan memandang ke audiens, kemudian arah pandangannya kembali ke selembar kertas yang dibawanya dengan membacakan beberapa masalah yang akan dibahas pada sidang hari ini. Sebelum masuk ke pembahasan, Jokowi diam selama 8 detik memberikan jeda disetiap kalimatnya. Posisi Jokowi tegak berdiri dan kedua tangan saling berpegangan di atas meja mimbar. Matanya setiap beberapa detik berkedip. Jokowi 
berpidato dengan berdiri, dan tidak nyaman bila terlalu lama berada pada satu titik tertentu, karena itu la sesekali mengangkat kakinya seperti mengganti posisi pijakan. Hal ini jelas terlihat dari badannya yang bergerak.Pidato pengantar Jokowi pada Sidang Kabinet Paripurna menggunakan bahasa yang mudah dipahami semua kalangan. Isi pesan yang ringan, menggunakan bahasa keseharian, mempersuasi secara baik, dan tegas.

\section{Gambar 2}

\section{Gerakan tangan Jokowi menunjuk Menteri Kelautan}

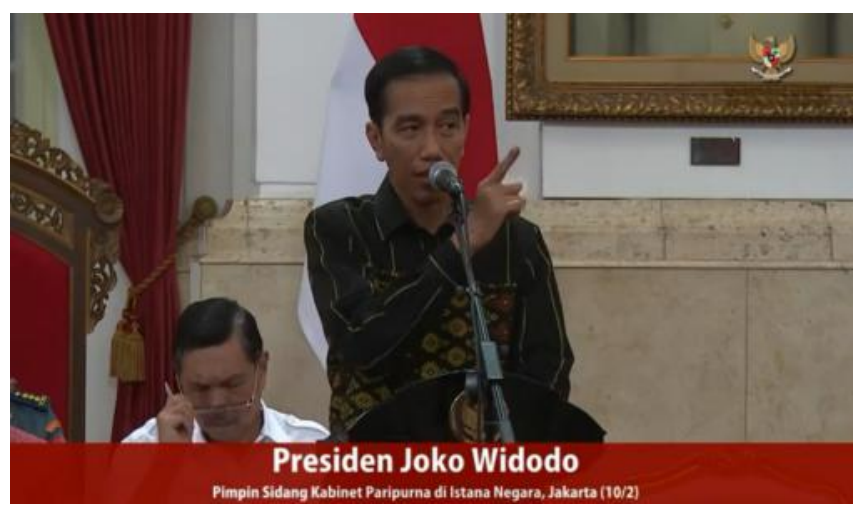

Sumber: Pidato Pengantar Jokowi pada Sidang Kabinet Paripurna 10Februari 2016 di Istana Negara, Jakarta diunduh dari https://www.youtube.com

Jokowi terlihat mengubah arah pandangannya, dari depan menengok ke audiens yang berada di bagian kanan beliau. Beberapa kali menengok untuk melakukan komunikasi dengan audiens. Jokowi juga melakukan kontak mata dengan audiens, seperti mengangkat alis pada saat menunggu jawaban dari audiens. Jokowi aktif melakukan gerakan untuk meyakinkan pidatonya. Hingga pada menit ke-7 Jokowi melihat catatan di meja mimbarnya kemudian mengakhiri pidatonya.

Hasil wawancara dengan Siswo Purnomo selaku protokoler walikota Semarang pada 28 April 2017, menjelaskan bahwa Jokowi lebih memperhatikan durasi dan efisiensi waktu. Dari sini bisa dilihat bahwa yang terpenting dalam penyampaian pidato yaitu materi pidato dapat tersampaikan ke audiens. Bukan masalah kuantitas tetapi kualitiasnya. Jokowi merupakan tipe orang yang tidak berbelit-belit sehingga lebih mengutamakan penggunaan bahasa yang lebih singkat dan tidak berpanjang lebar, namun tujuan dan maksud yang ingin disampaikan terdengar dengan lugas dan jelas.

Berbeda dengan SBY yang berlatar belakang kemiliteran, Jokowi lahir dari masyarakat biasa sehingga pidato Joko Widodo menggunakan bahasa yang mudah dipahami oleh semua kalangan. Terkadang diselingi dengan bahasa keseharian. Dalam menyampaikan pidatonya Jokowi lebih banyak memberikan contoh rill yang dihadapi sehingga pesan yang disampaikan dapat dengan mudah dipahami audiens.

Dalam menyampaikan pidatonya, Jokowi tidak menggunakan alat bantu gadget canggih seperti yang biasa digunakan mantan presiden Susilo Bambang Yudhoyono (SBY). Jokowi hanya membawa selembar kertas untuk membantu mengingat isi pidato yang disampaikan. Siswo Purnomo menilai bahwa Jokowi ingin lepas dari formalitas protokoleran 
yang terlalu resmi. Dari segi tindakan, Jokowi lebih sederhana, dalam arti beliau dalam berpidato posisinya berdiri artinya beliau menghormati audiens. Sedangkan dari segi pakaian Jokowi lebih santai menggunakan batik.

\section{b. Gaya Retorika Susilo Bambang Yudhoyono dan Joko Widodo Dikaitkan dengan Konsep Kode Verbal dan Non Verbal.}

Gaya (style) merupakan salah satu dari lima canon yang harus diikuti oleh pembicara agar sebuat pidato yang disampaikan lebih mengesankan. Dalam menganalisis gaya (style) retorika Susilo Bambang Yudhoyono dan Joko Widodo melalui video pidato pengantar sidang kabinet paripurna, penulis menggunakan teori kode verbal dan non verbal.

1. Analisis Kode Verbal Pidato Susilo Bambang Yudhoyono dan Joko Widodo pada Pidato Pengantar Sidang Paripurna

Hal pertama yang benar-benar harus diperhatikan dalam berpidato adalah penggunaan bahasa. Jika orator tidak mempergunakan bahasa dengan baik, belum tentu audiens bisa menyimak orator dengan baik. Percuma seorang orator menonjalkan sisi intelektual dengan memperkaya istilah, namun audiens tidak mampu memahaminya. Hal utama yang akan membuat audiens terhubung dengan orator adalah saat orator menggunakan bahasa yang mudah dipahami oleh audiens. Dalam Teori Bahasa, Ferdinand de Saussure membuat sebuah pembeda penting antara bahasa formal, yang disebut langue, dengan penggunaan bahasa yang sebenarnya dalam komunikasi, disebut parole. (Saussure dalamLittlejohn, 2009:156)

\section{a. Gaya Retorika Susilo Bambang Yudhoyono (SBY)}

Menurut teori bahasa Ferdinand de Saussure, bahasa yang digunakan SBY dalam berpidato termasuk langue. Langue adalah bahasa konvensional, bahasa yang sesuai ejaan yang telah disempurnakan, bahasa yang mengikuti tata aturan baku bahasa. Lebih jauh Saussure mengatakan bahwa langue merupakan keseluruhan kebiasaan (kata) yang diperoleh secara pasif yang diajarkan dalam masyarakat bahasa, yang memungkinkan para penutur saling memahami dan menghasilkan unsur-unsur yang dipahami penutur dan masyarakat. Langue bersenyawa dengan kehidupan masyarakat secara alami. (Saussure, 1993:155) Saussure meyakini bahwa peneliti linguistik harus memperhatikan hal yang membentuk bahasa, seperti bunyi pengucapan, kata-kata, dan tata bahasa. (Saussure dalamLittlejohn, 2009:156).

Fonologi (tata bunyi) merupakan bunyi terkecil yang membedakan arti, seperti pada pidato SBY ditemukan kata bias dan Nias, kedua bunyi /b/ dan /n/ adalah dua fonem yang membedakan arti. Namun, arti dari kedua kata tersebut dapat ditangkap audiensdengan benar karena bunyi pengucapan yang jelas oleh SBY (Susilo Bambang Yudhoyono). Dengan bunyi pengucapan yang jelas, kata yang berbeda makna dapat tertangkan sesuai dengan makna sebenarnya.

Morfologi merupakan pembentukan kata/ tata bentuk. Terdapat dua morfem, yaitu morfem terikat dan morfem bebas. Morfem terikat yang penulis dapatkan dari 
pidato SBY yaitu kata mendengarkan yang menggunakan kata penghubung "mekan" dari kata dasar "dengar". Contoh lain yang penulis dapat dari pidato SBY yaitu; penjelasan, mengulangi, mengelolanya, diusulkan, dll. Kedua, morfem bebas, yaitu morfem yang dapat berdiri sendiri sebagai kata serta secara gramatikal menduduki satu fungsi pada kalimat. Morfem bebas disebut juga kata dasar, contoh kata utama, resmi, jelas, harus, dll.

Sintaksis yaitu ilmu mengenai prinsip serta peraturan untuk membuat sebuah kalimat yang menganut aturan SPOK (Subjek, Predikat, Objek, Keterangan). Contoh kalimat yang digunakan SBY dalam pidatonya yaitu "saya perintahkan kepada kementerian dan lembaga yang merasa mendapatkan dana baru, anggaran baru, yang berasal dari dana optimalisasi agar dijaga akuntabilitasnya, governance-nya, dengan demikian tidak menimbulkan masalah baru." Subjek dalam kalimat tersebut adalah "saya (SBY)", Predikat "perintahkan", dan Objeknya "kementerian dan lembaga yang merasa mendapatkan dana baru, anggaran baru".

Dari penjelasan diatas, dalam menyampaikan pesan dengan bahasa Langue, SBY yang merupakan pembicara/ orator, sudah memenuhi 3 (tiga) hal yang membentuk bahasa (langue) yaitu fonologi, morfologi, dan sintaksis.

\section{b. Gaya Retorika Joko Widodo}

Menurut teori bahasa Ferdinand de Saussure, bahasa yang digunakan Jokowi dalam berpidato termasuk dalam bahasa percakapan (parole). Parole adalah bahasa tuturan, bahasa sehari-hari. Singkatnya, parole adalah keseluruhan dari apa yang diajarkan orang temasuk konstruksi-konstruksi individu yang muncul dari pilihan penutur, dan pengucapan-pengucapan yang diperlukan untuk menghasilkan konstruksi-konstruksi ini berdasarkan pilihan bebas juga. Parole merupakan manifestasi individu dari bahasa. (Saussure, 1993:06)

Bahasa parole dalam pidato Jokowi misalnya, sebagai berikut:

- "Wong kita belum ngerjain jalan kok, ini contoh loh ya, belum ngerjain jalan kok, ini baru ngerjain waduk kok, yasudah".

- "Ini yang menyebabkan anggaran kita hilang nggak berbekas. Karena duitnya mengikuti organisasi yang ada".

- "Sebuah direktur,memang belum ada prioritas kesana ya ndak usah diberi".

Jadi, parole adalah dialek. Parole bukan fakta sosial karena seluruhnya merupakan hasil individu yang sadar. Pemakaian kata "wong" (bahasa Jawa) dalam pidato Jokowi bermakna denotatif yaitu "orang" (dalam bahasa Indonesia), kata "nggak" dan "ndak" bermakna "tidak", kata "duit" bermakna "uang". Kata-kata tersebut termasuk bahasa non baku atau bahasa tutur, yaitu bahasa keseharian. Dalam pidato pengantar Presiden pada sidang kabinet paripurna 2017, Jokowi menggunakan kalimat sederhana, singkat, dan menggunakan kata-kata yang biasa digunakan sehari-hari. 
Saat menjadi pembicara perlu diperhatikan mengenai penggunaan kalimat. Apapun yang disampaikan orator harus efisien. Apabila dengan sepuluh kata audiens dapat memahami maksud yang disampaikan, tidak perlu orator berbicara dengan menghabiskan 100 kata atau lebih. Dilihat dari durasi yang dibutuhkan Jokowi untuk menyampaikan isi pidato, Jokowi masuk dalam golongan orator yang efisien dalam berpidato. Kalimat yang digunakan tidak terlalu panjang, namun seluruh isi pidato dapat tersampaikan.

Apapun yang orator sampaikan harus jelas. Ejaan benar sehingga dapat didengarkan dengan baik oleh audiens. Jokowi menggunakan bahasa Indonesia yang baik dan benar. Tidak hanya bahasa Indonesia, dalam pidatonya Jokowi menyelipkan bahasa jawa yang tidak bisa lepas dari daerah asalnya yaitu Kota Solo. Jokowi juga menggunakan bahasa asing dengan pronunciation benar, berlogat jawa.

\section{Analisis Kode Non Verbal Pidato Susilo Bambang Yudhoyono dan Joko Widodo pada Pidato Pengantar Sidang Paripurna}

Berdasarkan obyek yang akan diteliti dan teori yang sudah dipaparkan diatas, analisis dari penelitian ini adalah proses komunikasi non verbal dengan klasifikasi perilaku non verbal yakni bahasa tubuh (kinesics). Birdwhistell, Paul Ekman, dan Wallace Friesen menganalisis aktivitas non verbal dengan tiga cara, yaitu sumber asli perbuatan (origin), penandaan (coding), dan penggunaan. (Littlejohn, 2009:160)

Menurut Ekman dan Friensen, semua perilaku non verbal dapat digolongkan menjadi satu dari kelima jenis tersebut, bergantung pada sumber asli perbuatan (origin), penandaan (coding), dan penggunaan. Kelima tipe itu adalah emblem, ilustrator, adaptor, regulator, dan penunjukan perasaan (affect display). (Littlejohn, 2012:160)

\section{a. Gaya Retorika Susilo Bambang Yudhoyono (SBY)}

Tabel 4.1

Analisis kode non verbal Susilo Bambang Yudhoyono (SBY)

\begin{tabular}{|c|l|}
\hline Perilaku Non Verbal kinesics & \multicolumn{1}{|c|}{ Analisis } \\
\hline Emblem & $\begin{array}{l}\text { Lambang secara verbal dapat diartikan ke dalam makna } \\
\text { yang cukup tepat. Dari video pidato SBY, tidak ada gerakan } \\
\text { yang berdiri sendiri tanpa adanya komunikasi verbal yang } \\
\text { dilakukan. }\end{array}$ \\
\hline
\end{tabular}




\begin{tabular}{|c|c|}
\hline Illustrator & $\begin{array}{l}\text { Digunakan untuk menggambarkan apa yang telah dikatakan } \\
\text { secara verbal. } \\
\text { 1. Batons : SBY melakukan gerakan kepala dengan men- } \\
\text { gangguk yang menunjukkan tekanan pada pesan yang } \\
\text { disampaikan } \\
\text { 2. Ideographs : SBY melakukan gerakan menguncupkan } \\
\text { jari-jari tangan kiri pada waktu mengucapkan kata "saya } \\
\text { tangkap" } \\
\text { 3. Deitic Movements : SBY tidak melakukan gerakan yang } \\
\text { dimaksudkan untuk menunjukkan sesuatu } \\
\text { 4. Apatial Movements : tidak ada gerakan yang melukis- } \\
\text { kan besar atau kecilnya ruangan } \\
\text { 5. Kinetographs : tidak ada gerakan yang menggambarkan } \\
\text { gerakan fisik } \\
\text { 6. Rytmic Movements : SBY tidak melakukan gerakan yang } \\
\text { menunjukkan suatu irama tertentu } \\
\text { 7. Pictographs : SBY tidak melakukan gerakan yang meng- } \\
\text { gambarkan sesuatu di udara } \\
\text { 8. Emblematic Movements : SBY melakukan gerakan sep- } \\
\text { erti membuka tangan untuk menggambarkan pesan } \\
\text { yang disampaikan }\end{array}$ \\
\hline Adaptor & $\begin{array}{l}\text { Yang mengabdi untuk memudahkan pelepasan tekanan } \\
\text { fisik. } \\
\text { 1. Self Adaptor : SBY terlihat menyentuh dada. } \\
\text { 2. Alter Adaptor : SBY tidak melakukan perilaku yang ditu- } \\
\text { jukan kepada tubuh orang lain. Selama pidato, SBY tidak } \\
\text { melakukan sentuhan dengan audiens. } \\
\text { 3. Object-adapter : Membenarkan posisi iPad dan men- } \\
\text { goperasikannya. }\end{array}$ \\
\hline Regulator & $\begin{array}{l}\text { SBY hanya menyampaikan isi pesan dalam pidato dan tidak } \\
\text { ada tanya jawab dengan audiens sehingga perilaku yang di } \\
\text { tunjukkan SBY untuk mengendalikan atau mengkoordina- } \\
\text { sikan interaksi dengan audiens tidak terlihat dalam video } \\
\text { tersebut. }\end{array}$ \\
\hline Affect Display & $\begin{array}{l}\text { Perilaku ini melibatkan penunjukan perasaan dan emosi. } \\
\text { Wajah adalah sumber yang kaya untuk menunjukkan pen- } \\
\text { garuh, walaupun bagian tubuh lainnya juga terlibat. } \\
\text { SBY tidak menunjukkan ekspresi marah, namun ia berpidato } \\
\text { dengan tegas, ekspresi wajah serius dalam menyampaikan } \\
\text { masalah-masalah yang akan dibahas pada sidang kabinet } \\
\text { paripurna. }\end{array}$ \\
\hline
\end{tabular}

Sumber: olahan peneliti

Variabel komunikasi non verbal kinesics yang ditemukan dari hasil pengamatan video pidato pengantar Presiden Susilo Bambang Yudhoyono (SBY) pada Sidang Kabinet Paripurna lebih banyak yang masuk dalam klasifikasisasi, ilustrator, Adaptor dan affect display. 
Dari pengamatan gaya pidato Susilo Bambang Yudhoyono (SBY), Gerakan-gerakan ilustrator cenderung merupakan gerakan yang dilakukan oleh anggota tubuh dan tidak selalu disertai dengan mimik wajah (affect display) sebagai ekspresi pendukung dari gerakan non verbal yang dilakukan dan pesan yang disampaikan. SBY tidak aktif melakukan gerakan sehingga gerakan ilustrator tidak banyak ditemui. SBY cenderung tenang dalam berpidato dengan tangan menompang diatas meja, melakukan gerakan seperlunya, lebih berfokus pada kode verbal/ penggunaan bahasa yang tertata rapi yang tidak selalu didukung dengan kode non verbal. Mimik wajah (affect display) tidak berubah-ubah selama berpidato. Karena berlatar belakang kemiliteran, SBY selalu menunjukkan ekspresi wajah serius dalam setiap pidatonya.

Gerakan bahasa isyarat yang termasuk dalam klasifikasi Adaptor paling banyak ditemui pada video pidato SBY. Gerakan yang digunakan SBY untuk membantu meredakan ketegangan tubuh yaitu Object-adapter, yang merupakan sebuah perilaku yang ditujukan kepada benda. Dari pembukaan hingga penutupan pidato, gerakan Object-adapter yang dilakukan SBY ditujukan pada gadged canggih yang dibawanya. la lebih sering membenarkan posisi iPad-nya dan mengoprasikannya.

\section{b. Gaya Retorika Joko Widodo}

Tabel 4.2

Analisis kode non verbal Joko Widodo

\begin{tabular}{|c|l|}
\hline Perilaku Non Verbal kinesics & \multicolumn{1}{|c|}{ Analisis } \\
\hline Emblem & $\begin{array}{l}\text { Lambang secara verbal dapat diartikan ke dalam } \\
\text { makna yang cukup tepat. } \\
\text { Dari video pidato Jokowi, gerakan menaikkan alis } \\
\text { yang berdiri sen diri tanpa adanya komunikasi verbal } \\
\text { yang dilakukan Jokowi dapat diartikan sebagai tanda } \\
\text { memastikan jawaban audiens }\end{array}$ \\
\hline Illustrator & $\begin{array}{l}\text { Digunakan untuk menggambarkan apa yang telah di- } \\
\text { katakan secara verbal. } \\
\text { 1. } \begin{array}{l}\text { Batons : untuk menunjukkan tekanan pada } \\
\text { pesan yang disampaikan, Jokowi menggunakan } \\
\text { gerakan tangan. }\end{array} \\
\text { 2. } \begin{array}{l}\text { Ideographs : banyak gerakan tangan yang dilaku- } \\
\text { kan Jokowi untuk mengarahkan pikiran audiens }\end{array} \\
\text { 3. } \begin{array}{l}\text { Deitic Movements : Jokowi menunjuk ke arah } \\
\text { Menteri Kelautan untuk mengingatkan bahasa } \\
\text { yang digunakan dalam bersosialisasi dengan } \\
\text { para nelayan. }\end{array} \\
\text { 4patial Movements : Gerakan membuka kedua } \\
\text { tangan yang berarti semua atau dalam jumlah } \\
\text { banyak } \\
\text { Kinetographs : tidak ada gerakan yang meng- } \\
\text { gambarkan gerakan fisik }\end{array}$ \\
\hline
\end{tabular}




\begin{tabular}{|c|c|}
\hline Illustrator & $\begin{array}{l}\text { 6. Rytmic Movements : Jokowi tidak melakukan ger- } \\
\text { akan yang menunjukkan suatu irama tertentu } \\
\text { 7. Pictographs : Jokowi tidak melakukan gerakan } \\
\text { yang menggambarkan sesuatu di udara } \\
\text { 8. Emblematic Movements : Jokowi mengangkat } \\
\text { jari telunjuk, gerakan ini menggambarkan suatu } \\
\text { pernyataan verbal yang bermakna angka satu. }\end{array}$ \\
\hline Adaptor & $\begin{array}{l}\text { Yang mengabdi untuk memudahkan pelepasan } \\
\text { tekanan fisik. } \\
\text { 1. Self Adaptor : Jokowi terlihat mengusap kening } \\
\text { 2. Alter Adaptor : Jokowi tidak melakukan perilaku } \\
\text { yang ditujukan kepada tubuh orang lain. Selama } \\
\text { pidato, Jokowi tidak melakukan sentuhan den- } \\
\text { gan audiens. } \\
\text { 3. Object-adapter : Menata lembaran-lembaran } \\
\text { kertas yang dibawanya }\end{array}$ \\
\hline Regulator & $\begin{array}{l}\text { Perilaku yang di gunakan untuk mengendalikan atau } \\
\text { mengkoordinasikan interaksi. } \\
\text { Jokowi melakukan interaksi dengan audiens, melon- } \\
\text { tarkan beberapa pertanyaan sebagai berikut: } \\
\text { - "Di PU ada berapa dirjen?" } \\
\text { - "Kemudian satu dirjen ada, dibawahnya apala- } \\
\text { gi?" } \\
\text { - "Direktur ada berapa?" } \\
\text { - " } 1 \text { direktu ada berapa lagi dibawahnya apa?" } \\
\text { - "Habis kasubdit ada apalagi?" } \\
\text { Jokowi terlihat mengangkat alis ketika menunggu } \\
\text { jawaban dari para menteri. }\end{array}$ \\
\hline Affect Display & $\begin{array}{l}\text { Perilaku ini melibatkan penunjukan perasaan dan } \\
\text { emosi. Wajah adalah sumber yang kaya untuk } \\
\text { menunjukkan pengaruh, walaupun bagian tubuh } \\
\text { lainnya juga terlibat. } \\
\text { Disini Jokowi terlihat menunjukkan ekspresi kecewa } \\
\text { atas anggaran yang habis karena pembagian angga- } \\
\text { ran yang salah. }\end{array}$ \\
\hline
\end{tabular}

Sumber: olahan peneliti

Variabel komunikasi non verbal kinesics yang ditemukan dari hasil pengamatan video pidato pengantar Presiden Joko Widodo pada Sidang Kabinet Paripurna lebih banyak yang masuk dalam klasifikasisasi, emblem, ilustrator, dan affect display. Dapat dilihat juga pada tabel 3. mengenai hasil temuan data. Hal ini dikarenakan gerakan-gerakan emblem dan ilustrator cenderung merupakan gerakan yang dilakukan oleh anggota tubuh dan selalu disertai dengan mimik wajah (affect display) sebagai pendukung dari gerakan non verbal yang dilakukan. Gerakan-gerakan bahasa isyarat yang termasuk dalam klasifikasi ilustrator paling banyak ditemui karena digunakan untuk menggambarkan apa yang dikatakan secara 
verbal, bersifat sengaja (intentional), walaupun kita tidak selalu menyadarinya secara langsung.

Gerakan komunikasi non verbal ilustrator dengan penggunaan anggota tubuh atau lebih sering dengan gerakan tangan dalam penyampaian pesannya lebih memerlukan penegasan ulang dari apa yang digerakkan dengan komunikasi verbal atau gerakan bibir (oral) yang dilakukan oleh Jokowi.

Dilihat dari hasil pengamatan video pidato, Jokowi lebih aktif melakukan gerakan ilustrator untuk menunjukkan tekanan pada pesan yang disampaikan. Mimik wajah (affect display) Jokowi berubah-ubah mengikuti pesan yang disampaikan dan gerakan yang dilakukan.

\section{Simpulan}

\section{a. Gaya retorika SBY (Susilo Bambang Yudoyono)}

SBY (Susilo Bambang Yudoyono) adalah presiden keenam yang berhasil menjabat selama dua periode (2004-2014). Berlatar belakang kemiliteran, SBY mempunyai karakteristik pembawaan yang tegas, disiplin, dan gagah berani. Dalam menyampaikan materi pidato, gaya bicara SBY teratur, kaku, dan menggunakan istilah yang panjang. Bahasa yang digunakan SBY dalam berpidato termasuk langue atau bahasa yang mengikuti tata aturan baku bahasa. Sebagai pembicara yang menggunakan bahasa langue, SBY berhasil memenuhi tiga hal yang membentuk bahasa (langue) yaitu fonologi (tata bunyi), morfologi (pembentukan kata), dan sintaksis (pembentuk kalimat). Selain bahasa yang digunakan, bahasa tubuh (body language) juga penting dilakukan untuk mencapai kesuksesan dalam kegiatan public speaking. Berbeda dengan Jokowi, SBY tidak terlalu aktif melakukan gerakan, sehingga bahasa tubuh SBY tidak banyak terlihat. SBY lebih mengutamakan kode verbal dibandingkan dengan non verbal. Variabel komunikasi non verbal kinesics yang ditemukan, masuk dalam klasifikasi ilustrator, adaptor, dan affect display. Gerakan ilustrator cenderung merupakan gerakan yang dilakukan oleh anggota tubuh untuk menggambarkan apa yang telah dikatakan secara verbal. Mimik wajah (affect display) sebagai ekspresi pendukung dari gerakan non verbal, SBY menunjukkan ekspresi wajah serius dari awal hingga akhir pidato. Gerakan bahasa isyarat adaptor yang paling banyak ditemui terutama objek-adapter yang ditujukan pada gadget canggih yang dibawanya untuk membantunya mengingat isi materi pidato.

\section{b. Gaya retorika Joko Widodo}

Joko Widodo adalah Presiden ketujuh yang menggantikan SBY setelah menjabat selama dua periode. Tumbuh dari masyarakat biasa, gaya beretorika Jokowi sesuai dengan karakternya. Berbeda dengan SBY yang berpidato dengan bahasa formal (langue), Jokowi berpidato menggunakan bahasa percakapan (parole). Menggunakan bahasa keseharian dan mudah dipahami oleh semua kalangan, kata-kata yang merakyat, dan lebih to the point. Kekuatan Jokowi selain bahasanya yang mudah dipahami juga adalah bahasa tubuh (body language) Jokowi yang membantu memudahkan pesan pidato dapat tersampaikan dengan jelas. 
Selain bahasa lisan, Jokowi aktif melakukan bahasa non verbal kinesics yang masuk dalam klasifikasi emblem, ilustrator, dan effect display. Berbeda dengan SBY yang lebih sering melakukan gerakan bahasa isyarat adaptor, Jokowi lebih aktif melakukan gerakan ilustrator. Melakukan gerakan tangan dalam menyampaikan pesannya sebagai penegasan ulang dari apa yang disampaikan dengan bahasa lisan. Selain bahasa dan gerakan tubuh SBY yang berbeda dengan gaya retorika Jokowi, mimik wajah (Affect display) yang ditunjukkan SBY juga jauh berbeda. SBY tidak terlalu ekspresif dalam beretorika, sedangkan ekspresi Jokowi berubah-ubah mengikuti pesan yang disampaikan dan gerakan yang dilakukan.

Penelitian ini menyarankan agar peneliti selanjutnya lebih berfokus pada bagaimana khalayak menilai gaya retorika untuk melihat efektifitas pesan yang dihasilkan.

\section{Daftar Pustaka}

Bungin, Burhan. (2010). Penelitian kualitatif : komunikasi, ekonomi, kebijakan publik, dan ilmu sosial lainnya, cet.4. Jakarta: Kencana

Bungin, Burhan. (2007). Penelitian kualitatif : komunikasi, ekonomi, kebijakan publik, dan ilmu sosial lainnya.Jakarta: Kencana

Departemen Pendidikan dan Kebudayaan. (1990).Kamus Besar Bahasa Indonesia.Jakarta: Balai Pustaka

Djunaisih, S. Sunarjo. (1983). Komunkasi, Persuasi Dan Retorika. Yogyakarta: Liberty

Effendy, Onong Uchjana. (1984).Komunikasi Teori dan Praktek. Bandung: PT. Remaja Rosdakarya.

Harper, W. J. dan C. W. Hall. (1976). Dairy Technology and Enginering. The AVI Publishing Co.Inc.Westport. Conecticut.

Haryadi dan Zamzani. (2000).Peningkatan Keterampilan Berbahasa Indonesia. Jakarta: Depdikbud

Hendrikus, Dori Wuwur. (1991). Retorika: Terampil berpidato, berdiskusi, Berargumentasi, bernegosiasi. Yogyakarta:Penerbit Kanisius

Husein, Umar. (2005). Metode Penelitian. Jakarta: Salemba 4

Hybels, Saundra dan Richard L. Weaver II.(1979). Speech/ Communication, Edisi ke-2. New York: D Van Nostrand.

Jalaluddin, Rakhmat (2005). Metode Penelitian Komunikasi. Bandung: PT. Remaja Rosdakarya Junaiyah H. Matanggui, Zainal Arifin. (2001) Morfologi edisi 2. Jakarta: PT. Gramedia Widiasarana Indonesia, kompas Gramedia Building

Kaye, Michael. (1994). Communication Management. Sydney: Prentice Hall

Kriyantono, Rachmat. (2007). Teknik Praktis Riset Komunikasi. Jakarta: Kencana Prenada Media Group

Kartono, Kartini. (1994). Pemimpin dan Kepemimpinan, Apakah Pemimpin Abnormal itu?. Jakarta: PT. Raja Grafindo Persada. 
Littlejohn, Stephe W. dan Karen A. Foss.(2009). Teori Komunikasi (theories of human communication) edisi 9. Jakarta: Salemba Humanika.

Littletjohn, W Stephen. (2012). Teori Komunikasi. Jakarta: Salemba Humanika.Miles, Matthew dan Huberman, A. Michael. (1992). Analisis Data Kualitatif: Buku Sumber Tantang Metode-Metode Baru. Jakarta: UI Press.

Moleong, Lexy J. (2007). Metode Penelitian Kualitatif. Bandung: PT Remaja Rosdakarya Morissan, MA. (2013). Teori Komunikasi. Bogor: Penerbit Ghalia Indonesia.

Mulyana, Deddy. (2008). IImu Komunikasi Suatu Pengantar. Bandung: PT Remaja Rosdakarya. Musaba, Zulkifli.(2012). Terampil Berbicara. Yogyakarta: CV. Aswaja Pressindo.

Oka, I Gusti Ngurah dan Basuki. (1990). Retorika (Kiat Bertutur). Malang: Yayasan Asih Asah Asuh Malang (YA3 Malang).

Rahmat, Jalaluddin. (2001). Retorika Modern. Bandung :Remaja Rosdakarya.

Ramlan. (1987). Sintaksis IImu Bahasa Indonesia. Yogyakarta: Karyono.

Richard West, Lynn H. Turner. (2008). Pengantar Teori Komunikasi: Analisis dan Aplikasi. Jakarta: Salemba Humanika.

Richard West, Lynn H. Turner. (2007). Pengantar Teori Komunikasi. Jakarta: Salemba Humanika.

Samovar, Larry A. dan Richard E. Porter. (1991).Communication Between Culture. Balmont, California: Wadsworth.

Samovar, Porter, McDaniel. (1998). Komunikasi Lintas Budaya. Jakarta: Salemba Humanika.

Stephe W. dan Karen A. Foss.(2008). Teori Komunikasi. Jakarta: Salemba Humanika.

Supriyono, Arif dkk. (2012). Jokowi Tokoh Perubahan. Jakarta: Republik.

St. Y. Slamet dan Amir. (1996). Peningkatan Keterampilan Berbahasa Indonesia (Bahasa Lisan dan Bahasa Tertulis). Surakarta: Universitas Sebelas Maret.

Stokes, Jane. (2006).How Do You Do and Cultural Studies: Panduan untuk Melaksanakan I Penelitian dalam Kajian Media dan Budaya.Yogyakarta: Bentang.

Sugiyono. (2010). Metode Penelitian Kuantitatif Kualitatif \& RND. Bandung: Alfabeta.

Tarigan, Henry Guntur.(1971). Metode Penelitian Linguistik. Jogyakarta: Gajah Mada University Press.

Undang-Undang Dasar Negara Republik Indonesia tahun 1945

Yendra. (2016). Mengenal Ilmu Bahasa (Linguistik). Yogyakarta: Deepublish.

http://www.rhetoricring.com/overview/, diakses pada 17 Maret 2017, 11:45 WIB

http://m.liputan6.com/news/read/2362224/begini-gaya-bahasa-Jokowi-dan-sby-menurutpenerjemah-kepresidenan, diakses pada 18 April 2017, 07:12 WIB

https://www.youtube.com

http://m.viva.co.id/siapa/read/105-sby diakses pada 23 Mei 2017, 11:12 WIB 